responding (the emotional component of the memory) was reduced while declarative memory (knowledge about the event) was left intact. The data therefore point towards erasing the pain but not the knowledge of the trauma memory: an important ethical and clinical difference.

We need to challenge the erroneous public perception of a science seeking to 'erase' painful memories as such media headlines are obscuring the true interpretation of the data and what treatment development seeks. Such consideration may help prevent us from inadvertently misleading people (especially those who have suffered trauma) to believe that we are pursuing an 'eternal sunshine of the spotless mind'.

1 Kindt $\mathrm{M}$, Soeter $\mathrm{M}$, Vervliet B. Beyond extinction: erasing human fear responses and preventing the return of fear. Nat Neurosci 2008; 12: 256-8.

2 Schiller D, Monfils M, Raio C, Johnson DC, LeDoux JE, Phelps EA. Preventing the return of fear in humans using reconsolidation update mechanisms. Nature 2009; 463: 49-53.

3 Liao SM, Sandberg A. The normativity of memory modification. Neuroethics 2008: 1: 85-99.

Emily A. Holmes, Department of Psychiatry, University of Oxford, UK. Email: emily.holmes@psych.ox.ac.uk; Anders Sandberg, Future of Humanity Institute, University of Oxford, UK; Lalitha Iyadurai, Amersham Hospital, Buckinghamshire, UK

doi: 10.1192/bjp.197.5.414b conduct research we must pay attention to its findings, no matter how unwelcome. The current evidence supports the superiority of CMHTs, no matter how much that they may grate.

1 Singh SP. Early intervention in psychosis. Br J Psychiatry 2010; 196: 343-5.

2 Craig TKJ, Garety P, Power P, Rahaman N, Colbert S, Fornells-Ambrojo M, et al. The Lambeth Early Onset (LEO) Team: randomised controlled trial of the effectiveness of specialised care for early psychosis. BMJ 2004; 329 : 1067-70.

3 Petersen L, Jeppesen P, Thorup A, Abel MB, øhlenschlaeger J, Christensen $\mathrm{T} \varnothing$, et al. A randomised multicentre trial of integrated versus standard treatment for patients with a first episode of psychotic illness. BMJ 2005; 331: 602 .

4 Burns T, Catty J, Dash M, Roberts C, Lockwood A, Marshall M. Use of intensive case management to reduce time in hospital in people with severe mental illness: systematic review and meta-regression. BMJ 2007; 335: 336.

5 Killaspy H, Bebbington P, Blizard R, Johnson S, Nolan F, Pilling S, et al. The REACT study: randomised evaluation of assertive community treatment in north London. BMJ 2006; 332: 815-20.

6 Burns T. End of the road for treatment-as-usual studies? Br J Psychiatry 2009; 195: 5-6.

Tom Burns, Professor of Social Psychiatry, University of Oxford, Warneford Hospital Oxford OX3 7JX, UK. Email: tom.burns@psych.ox.ac.uk

doi: 10.1192/bjp.197.5.415

\section{Early intervention in psychosis}

Professor Singh is the expert on early intervention services and provides a characteristically scholarly and elegant reappraisal. ${ }^{1}$ Although I am surprised that the Lambeth Early Onset (LEO) ${ }^{2}$ and OPUS ${ }^{3}$ trials are interpreted as quite so definitive (when most of us read them as very promising but far from conclusive), I am reluctant to disagree with an admired colleague in his area of expertise. However, I must take issue with one conclusion in his 'future directions'. Singh argues that generic community mental health teams (CMHTs) have no evidence for them and that 'The logical next step in the move from institutions to community is from generic community teams to specialist teams'. In this I believe he is mistaken.

Community mental health teams suffer from having evolved before the era of intensive mental health services research. Nobody 'owns' them, so few have actively researched them; they have most often been the comparators in randomised controlled trials of other innovative specialist teams. Despite this, research-based conclusions can be drawn about their comparative effectiveness. The body of assertive outreach research is overwhelmingly greater than for any other specialised team. What a series of over 60 assertive outreach team trials shows is that reductions in in-patient care are more highly dependent on the nature of the comparator services than the experimental services. ${ }^{4}$ Where these comparator services are poor and fragmented there is a substantial reduction; where they are not, then there is little or no reduction. Often this has been where the comparator is a generic community team. ${ }^{5}$

We have rather myopically interpreted these findings as a failure to demonstrate superiority of the specialist team over CMHTs. However, 'As health services enter a period of economic austerity', 'we need to recognise that the findings tell us much more than that. What they demonstrate is that generic CMHTs have routinely matched the specialist teams in major outcomes yet for a significantly lower cost. ${ }^{6}$ They are, in short, more cost-effective and therefore currently our best buy.

Experimentation and innovation in specialised teams must continue if we are to progress. However, if we
Author's reply: Professor Burns rightly reminds us that, unlike specialist teams, community mental health teams (CMHTs) have never had strong advocates and have not been actively researched. His point about the wide variation in CMHT outcomes as comparators in trials illustrates this: lacking a clear role, responsibilities and remit, CMHTs have struggled to delineate what they do well, shed what they do not, and ensure that their staff keep up with the changing evidence base for therapeutic interventions. Specialist teams do not do anything special which is out of CMHT reach. Specialist teams are simply better placed to engage patients and deliver high-quality interventions because of the specialist focus that allows clinicians to develop and hone specialist skills. This is the history of improvements in medicine, where specialisation is both an outcome of academic advance and a vehicle for service improvement. It is in the nature of generic teams to deliver generic care; there is no evidence that pouring extra resources into CMHTs would turn them into specialist equivalents.

The latest National Institute for Health and Clinical Excellence (NICE) guidelines on schizophrenia reviewed the clinical and cost-effectiveness of CMHTs and concluded:

'Despite the fact that CMHTs remain the mainstay of community mental healthcare, there is surprisingly little evidence to show that they are an effective way of organising services. As such, evidence for or against the effectiveness of CMHTs in the management of schizophrenia is insufficient to make any evidence-based recommendations' (p. 336). ${ }^{1}$

The health economic review adds:

'The available evidence on health economics is unclear. The non-significant differences between standard care and CMHTs, and between pre-intervention period and intervention period, suggest that CMHTs provide no real cost savings or extra costs' (p. 337). $^{1}$

Reluctant as I am to disagree with an esteemed colleague, there is little evidence to support the superiority of CMHTs over specialised teams.

Our understanding of mental disorders and the complexity of treatment has moved on considerably from the time when CMHTs were originally established. In this rapidly changing world, it is difficult to see how generic teams can deliver all the recommendations of the 22 NICE guidelines in mental health. 
The 'conflict' between generalism and specialism is not restricted to psychiatry, it is writ large in the historical development of 20thcentury medicine. ${ }^{2}$ In the 21 st century, CMHTs need to evolve and innovate and carve out a niche where the generalist can flourish, either in primary care or in high-quality, rapid assessment teams that complement specialist services, rather than compete with them.

1 National Collaborating Centre for Mental Health. Core Interventions in the Treatment and Management of Schizophrenia in Primary and
Secondary Care (Update). National Institute for Health and Clinical Excellence, 2009.

2 Huddle TS, Centor R, Heudebert GR. American internal medicine in the 21st century: can an Oslerian generalism survive? J Gen Intern Med 2003; 18: $764-7$.

Swaran Singh, Professor of Social and Community Psychiatry, Health Sciences Research Institute, Warwick Medical School, University of Warwick, Coventry CV4 7AL, UK. Email: S.P.Singh@warwick.ac.uk

doi: 10.1192/bjp.197.5.415a

\section{Correction}

Impact of cannabidiol on the acute and psychotomimetic effects of smoked cannabis: naturalistic study. BJP, 197, 285-290. The title of the paper should read: Impact of cannabidiol on the acute memory and psychotomimetic effects of smoked cannabis: naturalistic study. The online version of this paper was corrected in deviation from print and in accordance with this correction.

doi: 10.1192/bjp.197.5.416 